\title{
Formulation and evaluation of Stevia oral hygiene preparation: A noble herbal toothpaste
}

\author{
Kuntal Das*, Tehseen Atchia Abdoolah and James Sounder \\ Krupanidhi College of Pharmacy, \#12/1, Chikkabellandur, Carmelaram Post, Varthur Hobli, Bangalore-560035, India
}

\section{Article Info}

Article history

Received 12 February 2019

Revised 30 March 2020

Accepted 5 April 2020

Published online 30 June 2020

Keywords

Antibacterial

Comparative study

Formulation

Stevia

Stability

Toothpaste

\begin{abstract}
Polyherbal toothpastes are gaining importance due to less side effects and maintain the healthy teeth than non herbal toothpastes but use of sole herbal in toothpaste formulation with multiple action is rare. The aim of the present research was to formulate and evaluate herbal toothpaste, prepared with Stevia extract. Four different formulations were prepared: $0.5 \%, 1.0 \%, 2 \%$ and $3 \%$. All the formulated toothpaste was satisfied with all the required conditions for avoiding halitosis, prevent dental caries and periodontal diseases. The formulated herbal toothpaste compared with marketed preparation. Various physical parameters were evaluated as per Bureau of Indian Standards (BIS), and International Conference on Harmonisation (ICH) guidelines and revealed F3 (2\% Stevia extract) was the better formulation with respect to various compiled results. The colour of F3 formulation was moss green, smooth in nature, relative density 11.098 , pH-7.12, extrudability- $96.2 \%$, good spreadability $(5.4 \mathrm{~cm} / \mathrm{sec})$, viscosity $(78302$ cP) and quite stable for 6 months. The antimicrobial activity is evaluated against both the Grampositive and Gram-negative bacteria and revealed formulated herbal toothpaste with $2.0 \%$ Stevia extract exhibited significant activity with the zone of inhibition against Gram-positive and Gramnegative bacteria at MIC of $20 \mu \mathrm{g} / \mathrm{ml}$. The result of this investigation showed better patronizing and engrossing passion over commercial preparation (non-herbal and herbal) with formulated natural Stevia toothpaste. The research was challenging and showed good scope in future dental research as well as economic to the World market for human use.
\end{abstract}

\section{Introduction}

From the ancient period of time, the toothpaste is used for oral care and oral hygiene maintenance. In Pharmaceutical Sciences, toothpaste is a type of dentifrice which is used to clean, and improve the teeth health based on the principle of abrasiveness. It helps to prevent the dental plaque and foul smell caused by the food particles from the teeth, aids in the removal of halitosis and releases active ingredients such as fluoride to aid in preventing gingivitis. The majority of the cleaning is performed by using the toothbrush with the help of excipients used in toothpaste (Neema et al., 2009; Mangilal and Ravikumar, 2016). Toothpastes are having their ability to deliver preventive and therapeutically active ingredients towards healthy teeth. Such agents are like fluoride, metal salts and pyrophosphate which are useful for calcium inhibition; reduce the growth of plaque, and also to treat dentine hypersensitivity along with dental hygiene. The design of toothpaste formulations first started in India and China during 300-500 BC. During that period, squashed bone, pulverized egg and clam shells, etc., were used as

Corresponding author: Dr. Kuntal Das

Professor, Krupanidhi College of Pharmacy, \#12/1, Chikkabellandur, Carmelaram Post, Varthur Hobli, Bangalore- 560035, India

E-mail: drkkdsd@gmail.com

Tel.: +91-9632542846

Copyright (C) 2020 Ukaaz Publications. All rights reserved.

Email: ukaaz@yahoo.com; Website: www.ukaazpublications.com abrasives for cleaning teeth. Thereafter, modern toothpaste formulations were developed in the 19th century and gradually modern toothpastes, are formulated with various formulations. There are many toothpastes are available in the market which are non-herbal and also with polyherbals. The ingredients that are used in toothpaste are active pharmaceutical ingredients, abrasives, humectants, detergents, binders, sweeteners, preservatives and antioxidants, and flavors (Mehata, 2015). Several non-herbal toothpastes are available in the market that contain various chemical preventive agents (mainly triclosan and chlorhexidine), beneficial effects in the control of plaque and to reduce or prevent oral disease and also added in mouth rinses to prevent gingivitis. But, these chemicals show undesirable side effects likely tooth staining and altered taste (De Oliveira et al., 2008; George et al., 2009 and Barnes et al., 2010). Some toothpastes are also contained fluoride in the form of sodium fluoride (NaF), mono-fluorophosphate (MFP), or stannous fluoride (SnF) (Davies et al., 2003) which are dangerous to the health, especially to the children. Some adverse side effects of over dosage of fluorides in toothpastes are red blood cell deformation, neurological disorders such as depression, abnormal sensations in toes and fingers, excessive thirst, headache, and reduction in immune response, etc. (Jha et al., 2011). Likewise, there are a number of materials, and their combinations are used in the formulation of toothpaste but they might damage teeth and gums. Hence, nowadays there is a need for safe, effective and 
well-formulated dentifrices. Herbal drugs are the alternate source of chemical-based toothpaste formulations because of easily soluble in saliva and the intensity of penetration of herbs in mucous membranes are more. Therefore, the focus turned towards the utilization of natural herbal plants in the formulation of toothpastes.

In the present study, wonder Stevia (Stevia rebaudiana Bert., belongs to Asteraceae family) leaves are used for innovative dental toothpaste formulation. The plant uses as natural sweeteners and sugar substitute but a non-caloric (Das, 2013). It has a miracle versatile therapeutic efficacy without any side effects. Many works of literature revealed its potential health benefits mainly antidiabetic, anticancer, hypoglycemic, oral contraceptive, cardiovascular, wound healing, hepatoprotective, anti-inflammatory, and antimicrobial activities. It is also used for weight loss, digestive and skin problems (Mourey, 1992; Ghosh et al., 2008; Das and Kathiriya, 2012, Das, 2013). Stevia cosmetic products are also formulated and available in the market where Stevia moisturizing gel, vanishing cream is reported with scientific research data (Das et al., 2009; Das et al., 2012). Traditionally, Stevia leaves are used in cuts, wounds, burns, acne, seborrhea, dermatitis, and psoriasis after topical application of aqueous Stevia extracts (Rita Elkins, 1997) and even reported that the consumption of Stevia prevents dental caries (Ma and Blanksma, 2015). Some polyherbal dental formulations are reported where Stevia is used as natural sugar substituted (Sharma et al., 2014) but not used as main ingredients as well as no comparative study reported with marketed formulations. Besides, it is full of the natural taste, having its own antimicrobial properties and provides tremendous protection against cavities and other dental and gum problems. Therefore, Stevia leaves are selected in the present study. There are limited studies available regarding the stability, safety and efficacy of Stevia herbal dentifrices, hence the present study was undertaken to formulate and assess Stevia toothpaste with other herbal and non-herbal marketed toothpaste and its effect on teeth hygiene.

\section{Materials and Methods}

\subsection{Ingredients}

Calcium carbonate (Balaji Chemicals), Glycerin, Peppermint oil, and Stevia aqueous extract.

\subsection{Collection of plant material}

Stevia leaves are collected from Ankur Nursery, Ripponpet (Shimoga, Karnataka), India, and further identified and authenticated by Dr. P. E. Rajasekharan, Principal Scientist, Indian Institute of Horticultural Research, Bengaluru, India.

\subsection{Formulation}

Stevia leaves $(100 \mathrm{~g})$ is extracted with hot maceration using aqueous solvent for 6-7 h, followed by filtration and evaporation to get a thick green paste of Stevia extract (Yield: $46.3 \%$ ). Calcium carbonate and glycerine are mixed in water and then the mixed solution is added dropwise into mortar containing Stevia extract and triturated well until a paste consistency is formed. Few drops of peppermint oil is added as a flavoring agent. Previous literature and acute oral toxicity study of Stevia extract showed the safety of Stevia extract is upto 5\% (Das et al., 2012) and has no adverse effects in the genotoxicity study and subchronic oral toxicity study (Zhang et al., 2017). Based on that, four different formulations using $0.5 \%, 1 \%, 2 \%$ and $3 \%$ of Stevia extract are prepared (Table 1 ) in the present study.

Table 1: Formulation of herbal dental tooth paste (for $50 \mathrm{~g}$ )

\begin{tabular}{|l|l|l|l|l|l|}
\hline Ingredients & \multicolumn{4}{|c|}{ Quantity taken } & Category \\
\hline & F1 (0.5\%) & F2 (1.0\%) & F3 (2.0\%) & $\mathbf{F 4 ( 3 \% )}$ & \\
\hline Stevia extract & $0.25 \mathrm{~g}$ & $0.5 \mathrm{~g}$ & $1.0 \mathrm{~g}$ & $1.5 \mathrm{~g}$ & Antimicrobial, sweetening, preservative and foaming agent \\
Calcium carbonate & $25 \mathrm{~g}$ & $25 \mathrm{~g}$ & $25 \mathrm{~g}$ & $25 \mathrm{~g}$ & Abrasive \\
Glycerin & $9.5 \mathrm{ml}$ & $9.5 \mathrm{ml}$ & $9.5 \mathrm{ml}$ & $9.5 \mathrm{ml}$ & Humectant \\
Peppermint oil & $0.5 \mathrm{ml}$ & $0.5 \mathrm{ml}$ & $0.5 \mathrm{ml}$ & $0.5 \mathrm{ml}$ & Flavouring agent \\
Water & $8.0 \mathrm{ml}$ & $8.0 \mathrm{ml}$ & $8.0 \mathrm{ml}$ & $8.0 \mathrm{ml}$ & Vehicle \\
\hline
\end{tabular}

\subsection{Evaluation parameter}

Various parameters were checked for both the lab formulation and marketed herbal and non-herbal toothpaste formulations.

\subsubsection{Appearance (Dhase et al., 2014)}

The lab formulated toothpaste and marketed toothpaste was subjected to evaluate color, odour, and taste of toothpaste when kept for a long period of time.

\subsection{2 $\mathrm{pH}$}

The $\mathrm{pH}$ of formulated herbal toothpaste was determined by using $\mathrm{pH}$ meter. Weighed $5 \mathrm{~g}$ of toothpaste placed in $100 \mathrm{ml}$ beaker. Added $10 \mathrm{ml}$ of boiled water and then cooled. A suspension is formed after vigorously stirred and then measured the $\mathrm{pH}$ of the suspension using pH meter (Khokra et al., 2011).

\subsubsection{Homogenecity}

Both the toothpaste formulations, i.e., lab-based and marketed formulations were tested by extrudes a homogenous mass from the collapsible tube by applied normal force at $27 \pm 2{ }^{\circ} \mathrm{C}$.

\subsubsection{Foam formation}

The foaming ability of formulated toothpaste was evaluated by taken $2 \mathrm{~g}$ of formulation with $10 \mathrm{ml}$ of water in $100 \mathrm{ml}$ of measuring cylinder. The initial volume was noted and then shaken for 10 times and the final volume of foam was noted by calculated differences.

\subsubsection{Determination of abrasive particles}

Extrude the formulations about $20 \mathrm{~cm}$ long on the butter paper repeatedly for ten collapsible tubes. Then with fingertip, pressed the contents of the entire length to check the presence of sharp and hard-edged abrasive particles. 


\subsubsection{Determination of moisture content}

$5 \mathrm{~g}$ of formulation placed in a porcelain dish and then dried the sample in an oven at $105^{\circ} \mathrm{C}$ for $30 \mathrm{~min}$ and finally, the percentage moisture content was calculated by considered loss of mass on drying to that of the weight of formulation taken initially.

Calculation

$\%$ by mass $=100 \mathrm{MD} / \mathrm{M}$

where, $\mathrm{MD}=$ Loss of mass $(\mathrm{g})$ on drying; $\mathrm{M}=$ Mass $(\mathrm{g})$ of the material taken for the test.

\subsubsection{Extrudability}

The formulated paste was filled in the standard capped collapsible aluminum tube ( 3 Nos) and sealed by crimping to the end. The weights of the tubes were recorded. The tubes were placed between two glass slides and were clamped. $500 \mathrm{~g}$ weight was placed over the slides and then the cap was removed. The amount of the extruded paste was then collected and finally, percent of the extruded paste was calculated from the weighed amount of sample extruded. The same method was followed for the marketed products. The per cent of the extruded paste from the tube was calculated ( $>90 \%$ extrudability: excellent, $>80 \%$ extrudability: good, $>70 \%$ extrudability: fair).

\subsubsection{Relative density}

Relative density was determined by weight in gram taken in $10 \mathrm{ml}$ formulation and $10 \mathrm{ml}$ distilled water using specific gravity determinations gravity bottle.

\subsubsection{Viscosity}

Brookfield Viscometer was used to determine the viscosity of the formulated and marketed toothpaste by using spindle number 4 at a $50 \mathrm{rpm}$ at a temperature of $25^{\circ} \mathrm{C}$.

\subsubsection{Spreadability}

$2 \mathrm{~g}$ of formulated paste was placed on the ground slide under study. The formulated paste placed in between two glass slides for $5 \mathrm{~min}$ to expel air and to provide a uniform film of the paste. The excess of the paste was scraped off from the edges. The top plate was then subjected to pull off $100 \mathrm{~g}$ of weight with the help of string attached to the hook and time (sec) required by the top slide to cover a distance of 6 $\mathrm{cm}$ was recorded. A short interval indicated better spreadability.

Calculation

$\mathrm{S}=\mathrm{M} \times \mathrm{L} / \mathrm{T}$

where,

$\mathrm{S}=$ Spreadability

$\mathrm{M}=$ Weight in the pan (tied to the upper slide)

$\mathrm{L}=$ Length moved by the glass slide

$\mathrm{T}=$ Time (sec) taken to separate the upper slide from the ground slide.

\subsubsection{Cleaning ability test}

Colored eggshells were taken. A toothbrush moistened with water and brushed on one side of eggshell for 5-10 strokes (each stroke is a complete back and forth motion). The eggshell was inspected, if any color was removed. The toothbrush was rinsed with water and a small drop of formulated toothpaste was placed on the brush. Another side of eggshell was brushed for 5-10 strokes. The eggshell was rinsed and results were recorded. The same procedure was repeated for marketed formulations (Raj et al., 2018).

\subsubsection{Stability testing}

The stability of the formulated toothpaste was checked by exposing the product at $45 \pm 2{ }^{\circ} \mathrm{C}$ for a period of 28 days and also further exposed to refrigerator conditions at $2-8^{\circ} \mathrm{C}$ for $24 \mathrm{~h}$. Further, accelerated stability study of prepared formulations was conducted at room temperature and also at $40^{\circ} \mathrm{C}$ for 0 th, 10 th, 20th, and 30th days and observed for various parameters (By using Remi Environmental Test Chamber, India).

\subsubsection{Tube inertness}

The toothpaste container shall not produce any corrosion or deterioration in normal storage conditions like the heating temperature at $45 \pm 2{ }^{\circ} \mathrm{C}$ for ten days. The internal surface of the tube was cut, opened for tube inertness and observed whether any sign of chemical attack occurred or deterioration happened in the container or not.

\subsubsection{Determination of fluoride ion}

Potentiometer containing fluoride ion-sensitive electrodes were used for the detection of fluoride ions. A graph was plotted on a log scale, based on the concentration of fluoride ( $\mathrm{x}$-axis) Vs potential in $\mathrm{mV}$ (y-axis). From the calibration curve, the fluoride ion concentration in the formulations was measured (in $\mathrm{mg}$ ).

Calculation

Fluoride ion concentration (ppm) $\mathrm{M}=2 \mathrm{a} \times 10000 \mathrm{a}=\mathrm{mg}$ of fluoride ion calculated from graph $\mathrm{M}=$ Mass of sample taken in gram.

\subsubsection{Determination of lead}

For this test, hydrogen sulfide is used for the formulated solution to produce colour. The intensity of color produced with the sample was compared with the standard lead solution.

\subsubsection{Microbial study}

The antibacterial activity of toothpaste was performed by the well-diffusion method as per the standard of the National Committee for Clinical Laboratory Standards. Mueller Hinton II plates were used for the study. Initially, plates were streaked with bacteria (both Gram (+ve) and Gram (-ve)), punches were made with $6 \mathrm{~mm}$ diameter into the medium using a sterile cork borer. The test bacterium was inoculated into all places (Two Gram-positive bacteria, Straphyloccus aureus ATCC 29737, Streptococcus pyogenes ATCC 13813, and two Gram-negative bacteria such as Pseudomonus aeruginosa ATCC 25619, Escherichia coli ATCC 8739). 5 gm of the formulation was dissolved in nutrient agar culture and volume adjusted to $100 \mathrm{ml}$ with the same medium. The wells of plates were filled with $0.5 \mathrm{ml}$ of formulation and then incubated for $24 \mathrm{~h}$ at $37^{\circ} \mathrm{C}$. The zone of inhibition (in $\mathrm{mm}$ ) was calculated for antibacterial activity.

\subsubsection{Statistical analysis}

The experimental results were triplicate and zone of inhibition were determined in $\mathrm{mm}$. All the results were statistically expressed as the mean \pm standard error of the mean (SEM). Values of $p<0.05$ were considered statistically significant. One-way ANOVA study was carried out for significance. Thereafter, Pareto analysis was done for the selection of the best lab formulation. 


\section{Results}

Various evaluation tests were carried out for lab formulated as well as marketed non-herbal and herbal toothpaste and all the results were tabulated together in Table 2.

\subsection{Appearance}

No variation in colour, odor and taste were observed for lab formulated as well as marketed toothpastes.

\section{$3.2 \mathrm{pH}$}

The $\mathrm{pH}$ of the formulated toothpaste was found to be in the range of 8.0-8.4.

\subsection{Homogenecity}

All formulations produced uniform distribution in the toothpaste and showed excellent homogenecity which is better than marketed formulations.

\subsection{Foam formation}

All formulations produced very good foam as compared to marketed formulations. Among the formulated tooth paste, $2 \%$ Stevia tooth paste showed better foam formation.

\subsection{Determination of abrasive particles}

The abrasiveness of marketing pastes was compared with lab formulated toothpaste and showed that formulated toothpaste was better than marketed products and among them, $2 \%$ formulation showed excellent abrasiveness than other formulations due to absent of any abrasive particles.

\subsection{Moisture content}

The percent of moisture content in lab formulated pastes showed the same percent of moisture as that of marketed herbal toothpaste.

\subsection{Extrudability}

All the formulations were evaluated for extrudability test and the result was compared with marketed formulations. The result was tabulated in Table 3 which indicated extrudability varied from 86.2 to $96.2 \%$ when $500 \mathrm{~g}$ of weight was applied on the tubes. F3 showed excellent extrudability.

\subsection{Relative density}

All the formulations were evaluated for relative density and the result was compared with marketed formulations. The result was tabulated in Table 2 which indicated relative density varied from 10.217 to 11.098 , whereas for marketed non-herbal and herbal product showed relative density of 10.014 and 10.268 , respectively.

\subsection{Viscosity}

The viscosity of formulated toothpaste was found to be in the range of $78302 \mathrm{cP}$ to $102000 \mathrm{cPs}$ which indicates that the paste is easily spreadable when compared to the marketed ones.

\subsection{Spreadability}

Spreadability for the formulated toothpastes was varied from 2.2 to $2.8 \mathrm{~cm} / \mathrm{sec}$ and found to be better than commercial toothpastes.

\subsection{Cleaning ability}

Both the formulated and commercial tooth pastes showed good cleaning ability when they tested on coloured eggshell (Figure 1).

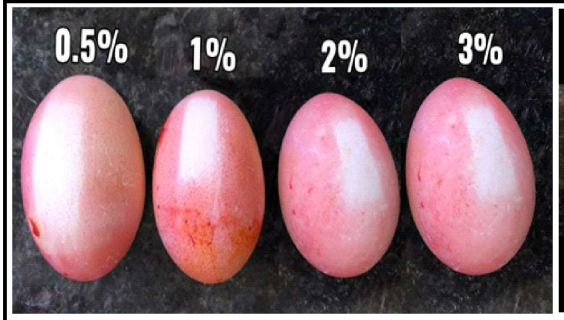

(a)

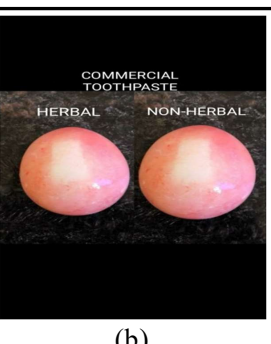

(b)
Figure 1: Cleaning ability of (a) formulated as well as (b) commercial tooth paste.

\subsection{Stability}

Initially, stability study of all the lab formulations was studied at $45 \pm 2{ }^{\circ} \mathrm{C}$ for 28 days and at $2-8^{\circ} \mathrm{C}$ for $24 \mathrm{~h}$, which resulted in good stability as compared to commercial toothpastes. Based on the study further, accelerated stability studies were carried out at $40^{\circ} \mathrm{C}$ $\pm 2{ }^{\circ} \mathrm{C}$ for various days' intervals up to one month (0th, 10 th, 20th, and 30th days). The result revealed that there were no changes in appearances, $\mathrm{pH}$ of the formulations and abrasiveness action, for all the formulations (Table 4), but slight changes of viscosity and spreadability observed with other formulations except formulation F3. The formulated toothpastes were observed to be stable even at refrigerated conditions.

\subsection{Tube inertness}

The internal part of all collapsible tubes showed no sign of corrosion or damage during normal storage conditions at a temperature of $45 \pm 2{ }^{\circ} \mathrm{C}$ for 10 days. So, it was confirmed that all the containers of different formulated tubes as well as marketed products showed good tube inertness.

\subsection{Determination of fluoride and lead}

Potentiometric fluoride ion-sensitive electrode was used for the detection of fluoride ions present in the formulated samples. The concentration ( $\mathrm{ppm}$ ) of fluoride ion in lab made formulations was negative as compared to marketed formulations. Marketed herbal toothpaste showed presence of $37 \mathrm{ppm}$ fluoride which was lesser than the standard value.

The color produced with hydrogen sulfide in the formulated pastes was negative whereas with marketed non-herbal toothpaste showed the presence of $2.4 \mathrm{ppm}$ lead but below the standard value. This revealed the safe usage of formulated toothpastes.

\subsection{Microbial study}

The microbial study was evaluated for lab formulated toothpastes by determining zone of inhibition in nutrient agar plates loaded with two Gram-positive (Straphyloccus aureus ATCC 29737, Streptococcus pyogenes ATCC 13813) and two Gram-negative bacteria (Pseudomonus aeruginosa ATCC 25619, Escherichia coli ATCC 8739) and showed active against both microbes (Figure 2) and revealed presence of antimicrobial property. The optimum value showed with F3, though the activity was concentrationdependent but F4 not significantly showed more zone of inhibition when compared with ampicillin as standard $(20 \mathrm{mcg} / \mathrm{ml})$. 
Table 2: Various physicochemical parameters and evaluation results

\begin{tabular}{|c|c|c|c|c|c|c|}
\hline \multirow[t]{2}{*}{ Parameters } & \multicolumn{4}{|c|}{ Formulated paste } & \multicolumn{2}{|c|}{ Marketed toothpaste } \\
\hline & F1 $(0.5 \%)$ & F2 (1\%) & F3 (2\%) & F4 (3\%) & Non-herbal & Herbal \\
\hline Colour & Tea & Sage & Moss green & Dark green & White & Off white \\
\hline Odour & Peppermint & Peppermint & Peppermint & Peppermint & Characteristic & Characteristic \\
\hline Taste & Less sweet & Sweet & Sweet & Sweet & Characteristic & Characteristic \\
\hline $\mathrm{pH}$ & $7.18 \pm 0.12$ & $7.14 \pm 0.02$ & $7.12 \pm 0.11$ & $7.21 \pm 0.30$ & $8.42 \pm 0.02$ & $7.96 \pm 0.13$ \\
\hline Homogenecity & Good & Good & Very good & Good & Good & Good \\
\hline Foamability & 10.4 (Good) & 10.9 (Good) & 12.4 (very Good) & 10.8 (Good) & 10.0 (Good) & 11.8 (Good) \\
\hline Abrasive particle & Absent & Absent & Absent & Absent & Absent & Present \\
\hline Abrasiveness & Moderate & Moderate & Very good & Good & Good & Good \\
\hline Moisture content & $14.39 \%$ & $14.20 \%$ & $15.18 \%$ & $14.89 \%$ & $14.32 \%$ & $15.02 \%$ \\
\hline Relative density & 10.610 & 10.817 & 11.098 & 10.577 & 10.014 & 10.861 \\
\hline Viscosity & $102000 \mathrm{cP}$ & $104000 \mathrm{cP}$ & $78302 \mathrm{cP}$ & $97211 \mathrm{cP}$ & $98000 \mathrm{cP}$ & $83114 \mathrm{cP}$ \\
\hline Spreadability & $\begin{array}{l}2.7 \pm 0.13 \\
\mathrm{~cm} / \mathrm{sec}\end{array}$ & $\begin{array}{l}2.2 \pm 0.03 \\
\mathrm{~cm} / \mathrm{sec}\end{array}$ & $\begin{array}{l}5.4 \pm 0.21 \\
\mathrm{~cm} / \mathrm{sec}\end{array}$ & $\begin{array}{l}2.8 \pm 0.10 \\
\mathrm{~cm} / \mathrm{sec}\end{array}$ & $\begin{array}{l}3.6 \pm 0.22 \\
\mathrm{~cm} / \mathrm{sec}\end{array}$ & $\begin{array}{l}4.1 \pm 0.20 \\
\mathrm{~cm} / \mathrm{sec}\end{array}$ \\
\hline Cleaning ability & Moderate & Good & Very good & Good & Good & Good \\
\hline $\begin{array}{l}\text { Stability study at } 45 \pm 2^{\circ} \mathrm{C} \\
\text { for } 28 \text { days }\end{array}$ & Good & Good & Good & Good & Good & Good \\
\hline $\begin{array}{l}\text { Stability study at } 2-8^{\circ} \mathrm{C} \\
\text { for } 24 \mathrm{~h}\end{array}$ & Good & Good & Good & Good & Good & Good \\
\hline $\begin{array}{l}\text { Tube inertness at } 45 \pm 2{ }^{\circ} \mathrm{C} \\
\text { for } 10 \text { days }\end{array}$ & No corrosion & No corrosion & No corrosion & No corrosion & Slight corrosion & No corrosion \\
\hline Fluoride ion & Not detected & Not detected & Not detected & Not detected & Not detected & $37 \mathrm{ppm}$ \\
\hline Lead ion & Not detected & Not detected & Not detected & Not detected & $2.4 \mathrm{ppm}$ & Not detected \\
\hline
\end{tabular}

- Mean of three readings (Mean \pm SEM).

Table 3: Evaluation of extrudability

\begin{tabular}{|c|c|c|c|c|c|c|}
\hline \multirow[t]{2}{*}{ Extrudability } & \multicolumn{4}{|c|}{ Formulated paste (Mean of three tubes) } & \multicolumn{2}{|c|}{ Marketed toothpaste } \\
\hline & F1 $(0.5 \%)$ & F2 (1\%) & F3 (2\%) & F4 (3\%) & Non-herbal & Herbal \\
\hline Net wt of formulation $(\mathrm{g})$ & 50 & 50 & 50 & 50 & 50 & 80 \\
\hline $\begin{array}{l}\text { Wt of paste extruded } \\
\text { from tube }(\mathrm{g})\end{array}$ & $44.6 \pm 0.01$ & $43.9 \pm 0.15$ & $48.1 \pm 0.21$ & $43.1 \pm 0.32$ & $47.2 \pm 0.12$ & $72.7 \pm 0.22$ \\
\hline$\%$ content Extrudability & 89.2 & 87.8 & 96.2 & 86.2 & 94.4 & 90.8 \\
\hline
\end{tabular}

- Mean of three readings (Mean $\pm \mathrm{SEM}$ ).

Table 4: Accelerated stability study (after 30 days)

\begin{tabular}{|c|c|c|c|c|c|c|}
\hline \multirow[t]{2}{*}{ Stability study } & \multicolumn{4}{|c|}{ Formulated paste (Mean of three tubes) } & \multicolumn{2}{|c|}{ Marketed toothpaste } \\
\hline & F1 $(0.5 \%)$ & F2 (1 \%) & F3 (2\%) & F4 (3\%) & Non-herbal & Herbal \\
\hline \begin{tabular}{|l} 
Colour \\
Odour \\
Taste \\
pH \\
abrasiveness action
\end{tabular} & $\begin{array}{l}\text { No change } \\
\text { No change } \\
\text { No change } \\
7.16 \pm 0.02 \\
\text { Moderate }\end{array}$ & $\begin{array}{l}\text { No change } \\
\text { No change } \\
\text { No change } \\
7.13 \pm 0.11 \\
\text { Moderate }\end{array}$ & $\begin{array}{l}\text { No change } \\
\text { No change } \\
\text { No change } \\
7.12 \pm 0.01 \\
\text { Very good }\end{array}$ & $\begin{array}{l}\text { No change } \\
\text { No change } \\
\text { No change } \\
7.20 \pm 0.11 \\
\text { Good }\end{array}$ & $\begin{array}{l}\text { No change } \\
\text { No change } \\
\text { No change } \\
8.37 \pm 0.30 \\
\text { Good }\end{array}$ & $\begin{array}{l}\text { No change } \\
\text { No change } \\
\text { No change } \\
7.94 \pm 0.23 \\
\text { Good }\end{array}$ \\
\hline
\end{tabular}

- Mean of three readings (Mean $\pm \mathrm{SEM})$.

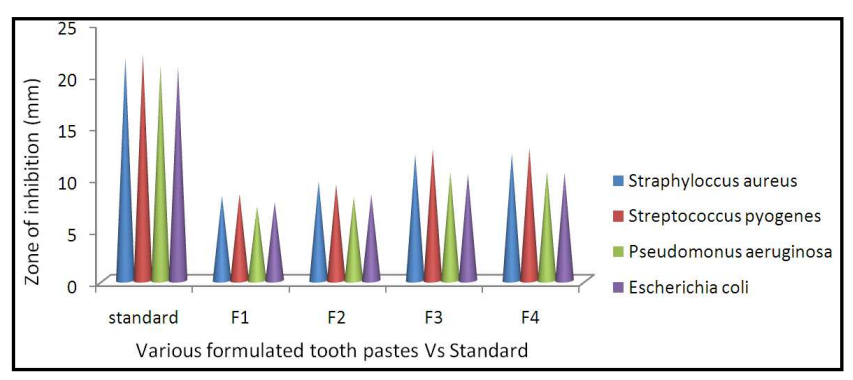

- Mean \pm SEM; $(n=3)$, one-way ANOVA study, all data compared with standard ampicillin; $* * * p<0.0001=$ high significant

Figure 2: Antimicrobial activity of Stevia extracts containing tooth paste formulations.
Statistical parameter for antimicrobial study

\begin{tabular}{|l|l|}
\hline $\boldsymbol{p}$ value & $\boldsymbol{p}<\mathbf{0 . 0 0 0 1}$ \\
\hline$p$ value summary & $* * *$ \\
Are means signif. different? $(p<0.05)$ & Yes \\
Number of groups & 5 \\
$\mathrm{~F}$ & 138.3 \\
$\mathrm{R}$ squared & 0.9736 \\
\hline
\end{tabular}

\section{Selection of best formulation}

Pareto analysis was carried out for the selection of best toothpaste formulation prepared in lab-based on few parameters, viz., $\mathrm{pH}$, Foamability, Moisture content, Relative density, Viscosity, Spreadability and percentage content extrudability and revealed F3 (2\%) Stevia extract containing toothpaste was better than other formulations (Figure 3 ) when the analysis was done in a scale of $80 / 20$ on the evaluation the above said parameters. 


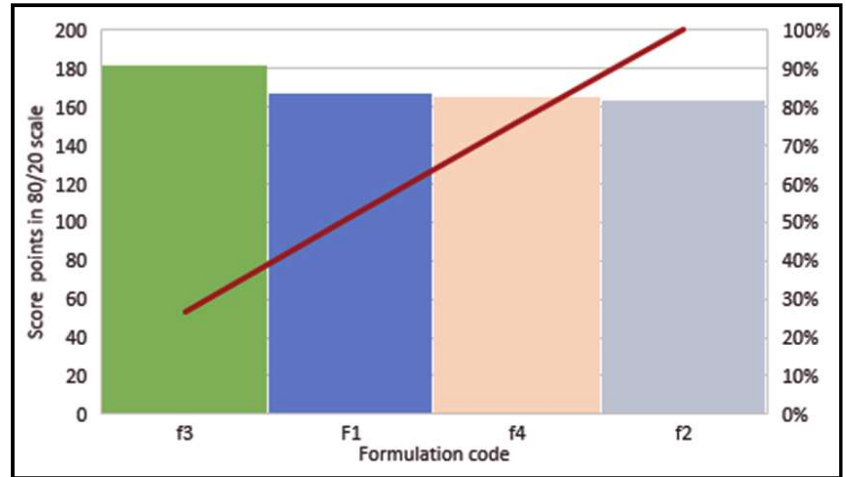

Figure 3: Pareto analysis for the selection of best formulation of Stevia toothpaste.

\section{Discussion}

Evaluation tests of toothpaste were carried out according to the standards specified by the Bureau of Indian standards IS 6356-1993 for formulated herbal toothpastes and compared with market formulations (non-herbal and herbal commercial toothpaste). As per BIS, all the results of formulated toothpaste were complied and they found to be of good quality and among them F3 (2\% Stevia extract) showed better.

The lab formulated tooth pastes showed almost constant $\mathrm{pH}$, homogeneous, spreadability appearance, and abrasiveness action. This was confirmed with the 30 days of the stability study. Formulation 3, contains 2\% Stevia extract showed better formulation than others as well as compared to commercial formulations when Pareto test was performed. In the present study, the extract of Stevia was selected due to its wide range of health benefits. Stevia rebaudiana Bert. is a South American plant belongs to family Asteraceae. Several literatures revealed the broad-spectrum antimicrobial activity of Stevia extract (Tadhani and Subhash, 2006; Ghosh et al., 2008; Das et al., 2009). Stevia extract contains stevioside which has remarkable stability in aqueous solutions over a wide range of $\mathrm{pH}$ values and temperature (Panpatil and Polasa, 2008; Abou Arab et al., 2010) and even it has no allergic reaction when it used as food sweetener or preservative (Pol et al., 2007). Thereafter, in water extract, the major components such as quercetin dehydrate, protocatechnic acid, and quercetin glycosyl are present which act as protective effects (Tadhani et al., 2007). Furthermore, S. rebaudiana extract possesses high antioxidants as well as a good antifungal activity too (Ghanta et al., 2007; Ruiz et al., 2015; AbdelFattah et al., 2018; Muradashvili et al., 2019). Stevia extract was also reported as an inhibitory effect on the caries-producing properties of Streptococcus sobrinus (Triratana et al., 2006). Some polyherbal formulation containing Stevia extract was prepared and tested for antimicrobial activity as Stevia inhibits the growth of dental caries causing microorganisms (Mehta et al., 2016). Ajagannanavar et al. (2014) were also reported an effectiveness of higher MIC concentration of Stevia (both aqueous and alcoholic) against Streptococcus mutans and Lactobacillus acidophilus. Dental caries occur due to specific bacteria that already residing in mouths and fermentable carbohydrates such as sugars and starches. With these two combinations, the bacteria metabolize these carbohydrates into organic acids which cause the erosion of enamel and cause dental fluorosis. In this case, Stevia extract is very much useful in restoring dental health rather than destruction because it is used as non-caloric sugar supplement and does not contain fermentable carbohydrates and acts as nonacidogenic (Brambilla et al., 2014). Though, the fluoride is required as a prescribed limit but in the present formulated toothpaste, fluoride content was not detected and that deficiency was fulfilled with Stevia's natural properties. Formulated toothpaste samples were not detected for lead content which met the specification for the lead content prescribed by the BIS limit of $0.002 \%$ (20 ppm) and British Standards for consumer product safety limit of $0.0005 \%$ (5 ppm) for toothpaste (Singh et al., 2014). Thereafter, fluoride content was absent in all the formulated toothpaste. It was revealed that fluoride based toothpastes are available as low fluoride (500 ppm), standard fluoride (1100-1500 ppm) and high fluoride toothpaste (>1500 ppm) (Ullah et al., 2017), but as per the fluoride poisoning data collected by the American Association of Poison Control (AAPC), more than $80 \%$ of the fluoride toxicity cases were reported in children below the age of 6 due to the swallowing reflex (Martínez-Mier, 2012). This created health problems such as nausea, vomiting occasionally with blood, abdominal pain, diarrhea, weakness, and hypocalcemia. Sometimes it also causes dental fluorosis, hypersensitivity reactions, dyspepsia, etc. (WHO, 2014). The lab formulated toothpaste is totally fluoride-free and, hence any age group of people can use for oral hygiene. Furthermore, the toothpaste has some unique properties such as the herbal parts are highly concentrated and readily soluble in saliva, the power to penetrate mucous membranes is more than 100 times that of natural toothpowders. It is full of the natural taste and freshness of herb without using any extra mouth wash. The formulated toothpastes are free from artificial flavors and gelatin, but provide better protection against cavities, tooth decay, and other dental and gum problems.

Hence, toothpaste with Stevia extract is beneficial to human oral hygiene and the prepared lab formulation was safe, stable and effective.

\section{Conclusion}

Stevia extract containing herbal toothpaste was formulated with selected suitable ingredients. Evaluation and comparison of results (as the standards specified by Bureau of Indian standards) with commercial herbal and non-herbal toothpastes are demonstrated that formulated toothpaste in Lab was having better patronizing and engrossing passion over the marketed formulations. Various physical parameters such as pH, Foamability, Moisture content, Relative density, Viscosity, Spreadability and percentage content extrudability studies and also antimicrobial activity demonstrated that lab made $2 \%$ Stevia extract containing herbal toothpaste was more efficacious, stable and safe as compared to other three formulations $(0.5 \%, 1.0 \%$ and $3.0 \%$ ) and even two commercially popular toothpastes.

\section{Conflict of interest}

The authors declare that there are no conflicts of interest in the course of conducting the research. All the authors had final decision regarding the manuscript and decision to submit the findings for publication. 


\section{References}

Abdel-Fattah, S. M.; Noah Badr, A.; Abu Seif, F. A. H.; Mohamed Ali, S. and Ahmed Hassan, R. (2018). Antifungal and anti-mycotoxigenic impact of eco-friendly extracts of wild Stevia. J. Biol. Sci., 18(8):488-499.

Abou-Arab, A.; Abou-Arab, A. and Abu-Salem, M. F. (2010). Physico-chemical assessment of natural sweeteners steviosides produced from Stevia rebaudiana Bertoni plant. African Journal of Food Science, 4:269-281

Ajagannanavar, S. L.; Shamarao, S.; Battur, H.; Tikare, S.; Al-Kheraif, A. A. and AIS ayed, M. S. A. E. (2014). Effect of aqueous and alcoholic Stevia (Stevia rebaudiana) extracts against Streptococcus mutans and Lactobacillus acidophilus in comparison to chlorhexidine: An in vitro study. J. Int. Soc. Prevent Communit Dent., 4(5):116-121.

Barnes, V. M.; Richter, R. and DeVizio, W. (2010). Comparision of the shortterm antiplaque/antibacterial efficacy of two commercial dentifrices. J. Clin. Dent., 21:101-104.

Brambilla, E.; Cagetti, M. G.; Ionescu, A.; Campus, G. and Lingstrom, P. (2014). An in vitro and in vivo comparison of the effect of Stevia rebaudiana extracts on different caries-related variables: A randomized controlled trial pilot study. Caries Res., 48:19-23.

Das, K. (2013). Wound healing potential of aqueous crude extract of Stevia rebaudiana in mice. Revista Brasileira de Farmacognosia, 23(2):351-357.

Das, K. and Kathiriya, A. K. (2012). Hepatoprotective activity of Stevia rebaudiana Bert. leaves against thioacetamide induced toxicity. Turkish Journal of Pharmaceutical Sciences, 9(3):343-352.

Das, K.; Dang, R. and Gupta, N. (2009). Comparative antimicrobial potential of different extracts of leaves of Stevie rebaudiana Bert., International Journal of Natural and Engineering Sciences, 3(1):59-62.

Das, K.; Dang, R. and Manjunath, U. M. (2009). Formulation and evaluation of a novel herbal gel of Stevia extract. Iranian Journal of Dermatology, 12(4): $117-122$.

Das, K.; Dang, R.; Manjunath, U. M.; Ugandar, R. E. and Lalitha, B. R. (2012). Evaluation for safety assessment of formulated vanishing cream containing aqueous Stevia extract for topical application. Indian J. of Novel Drug Delivery, 4(1):43-51.

Davies, R.; Ellwood, R. P. and Davies, G. W. (2003). The rational use of fluoride toothpaste. Int. J. Dent. Hyg., 1:3-8.

De Oliveira, S. M.; Torres, T. C.; Pereira, S. L.; Mota, O. M. and Carlos, M. X. (2008). Effect of dentifrice containing Aloe vera on plaque and gingivitis control. A double-blind clinical study in humans. J. Appl. Oral. Sci., 16:293-296.

Dhase, A.; Khadabadi, S. and Saboo, S. (2014). Formulation and evaluation of vanishing herbal cream of crude drug; American J. Eethnomedicine, 5:313-318.

George, J.; Hegde, S.; Rajesh, K. S. and Kumar, A. (2009). The efficacy of a herbal-based toothpaste in the control of plaque and gingivitis: A clinic-biochemical study. Indian J. Dent. Res., 20:480-482.

Ghanta, S.; Banerjee, A.; Poddar, A. and Chattopadhyay, S. (2007). Oxidative DNA damage preventive activity and antioxidant potential of Stevia rebaudiana (Bertoni) Bertoni, a natural sweetener. J. Agric. Food Chem., 55:10962-10967.

Ghosh, S.; Subudhi, E. and Nayak, S. (2008). Antimicrobial assay of Stevia rebaudiana Bertoni leaf extracts against 10 pathogens. Int. J. Integr. Biol., 2:27-31.

Jha, S. K.; Mishra, V. K.; Sharma, D. K. and Damodaran, T. (2011). Fluoride in the environment and its metabolism in humans anonymous reviews of environmental contamination and toxicology. New York: Springer, pp:121-142.

Khokra, S.; Sahu, R. K. and Jangle, R. (2011). Preparation and evaluation of herbal cosmetic cream, Pharmacologonline, 2:1258-1264.
Ma, M. S. and Blanksma, N. G. (2015). Stevia in the fight against dental caries. Ned Tijdschr Trandheelkd., 122(1):51-55.

Mangilal, T. and Ravikumar, M. (2016). Preparation and evaluation of herbal toothpaste and compared with commercial herbal toothpastes: An in vitro study. International Journal of Ayurvedic and Herbal Medicine, 6:2266-2251.

Martínez-Mier, E. A. (2012). Fluoride: Its metabolism, toxicity, and role in dental health. J. Evid. Based Complement Alternat. Med., 17:28-32.

Mehata, R. M. (2015). A textbook of pharmaceutics-II. Vallabh Prakashan, 5th edition. pp:215-218.

Mehta, R.; Pundir, R. M.; Sakhare, D. and Sharma, A. K. (2016). Herbal formulation against dental caries causing micro-organisms using extracts of Stevia rebaudiana leaves (A natural sweetner). The Natural Products Journal, 6:126-133.

Mourey, D. (1992). Life with Stevia: How sweet it is. Nutritional and Medicinal Uses.

Muradashvili, M.; Jabnidze, N.; Koiava, L.; Dumbadze, R.; Memarne, K.; Gorgiladze, L.; Meparishvili, G.; Kalandia, A. and Davitadze, R. (2019). Antibacterial and antifungal activity of Stevia rebaudiana (Asteraceae) leaf extract in vitro condition. Biological Forum: An International Journal, 11(1):212-216.

Nema, R. K.; Rathore K. S. and Dubey. B. K. (2009). A textbook of cosmetics. CBS Publisher and Distributor, 1st edition.

Panpatil, V. V. and Polasa, K. (2008). Assessment of Stevia (Stevia rebaudiana)-natural sweetener: A review. J. Food Sci. Technol., 45(6): 467-473.

Pol, J., Hohnová, B. and Hyotylainen, T. (2007). Characterisation of Stevia rebaudiana by comprehensive two dimensional liquid chromatography time-of-flight mass spectrometry. J. Chromatogr. A., 1150:85-92.

Raj, V. T.; Soundarya, P. H.; Babu, A. N. and Prakash, K. (2018). Formulation and evaluation of novel organic toothpaste using cow dung coal powder. Journal of Pharmacy Research, 12(2):227-230.

Rita Elkins, M. H. (1997). Stevia nature's sweeteners. Woodland Publishing, Inc. (Web article), pp:1-29.

Ruiz, J. C.; Ordonez, Y. B. M.; Basto, A. M. and Campos, M. R. S. (2015). Antioxidant capacity of leaf extracts from two Stevia rebaudiana Bertoni varieties adapted to cultivation in Mexico. Nutr. Hosp., 31(3): $1163-1170$.

Singh, N. K.; Audit, A.; Anthony, M.; Singh, A,; Sindhu, S. and Venkatesh, T. (2014). Lead in toothpaste. Biomedical. Sci. and Tech., 67:21579-21580.

Tadhani, M. B., Patel, V. H. and Subhash, R. (2007). In vitro antioxidant activities of Stevia rebaudiana leaves. J. Food Comp. Anal., 20:323-329.

Tadhani, M. B. and Subhash, R. (2006). In vitro antimicrobial activity of Stevia rebaudiana Bertoni leaves. Tropical Journal of Pharmaceutical Research, 5(1):557-560.

Triratana, T.; Suwannawong, S. K.; Srichan, R. and Surarit, R. (2006). Inhibitory effect of xylitol and Stevia extract on Streptococcus sobrinus. Abstract presented at the International Association for Dental Research General Sessions and Exhibition; Brisbane; Jun 28-Jul 1.

Ullah, R.; Zafar, M. S. and Shahani, N. (2017). Potential fluoride toxicity from oral medicaments: A review. Iran J. Basic Med. Sci., 20(8):841-848.

World Health Organization (2014). Basic methods for assessment of renal fluoride excretion in community prevention programmes for oral health. Geneva: World Health Organization.

Zhang, Q.; Yang, H.; Li, Y.; Liu, H. and Jia, X. (2017). Toxicological evaluation of ethanolic extract from Stevia rebaudiana Bertoni leaves: Genotoxicity and subchronic oral toxicity. Regulatory toxicology and Pharmacology, 86:253-259.

Citation: Kuntal Das, Tehseen Atchia Abdoolah and James Sounder (2020). Formulation and evaluation of Stevia oral hygiene preparation: A noble herbal tooth paste. Ann. Phytomed., 9(1):91-97. http://dx.doi.org/10.21276/ap.2020.9.1.10 